\title{
Strategies to encourage physical activity in patients with Parkinson's disease: improving quality of life
}

This article was published in the following Dove Press journal:

Journal of Parkinsonism and Restless Legs Syndrome

26 April 2016

Number of times this article has been viewed

\author{
Heather Barksdale' \\ Odinachi Oguh ${ }^{2}$ \\ 'Department of Rehabilitation, \\ University of Florida College of \\ Medicine, Jacksonville, FL, USA; \\ ${ }^{2}$ Department of Neurology, University \\ of Florida, Jacksonville, FL, USA
}

Correspondence: Odinachi Oguh Department of Neurology, University of Florida College of Medicine, 580 West 8th Street, Tower I, 9th Floor, Jacksonville, FL 32209, USA Email Odinach.Oguh@jax.ufl.edu

\begin{abstract}
The purpose of this article is to discuss strategies to encourage physical activity in patients with Parkinson's disease (PD), to consider the effect that physical activity and exercise has on the quality of life in individuals with PD, identify types of physical activity and exercise most recently and best supported by research, and to explore ways to customize physical exercise to PD patients based on stage and severity. Through research, recommendations are made to encourage physical activity and overcome barriers that may hinder participation in physical activity and exercise across different stages of PD.
\end{abstract}

Keywords: Parkinson's disease, physical activity, barriers, exercise, quality of life

\section{Introduction}

Parkinson's disease (PD) is a chronic and progressive neurodegenerative disorder of the basal ganglia, characterized by neuronal loss predominantly involving the substantia nigra and striatal dopaminergic neurons. Failure of normal dopamine connections result in abnormal downstream basal ganglia synaptic connections, some of which are modulated through glutamatergic pathways. ${ }^{1-3}$ This pathological process can lead to the cardinal signs of PD including: bradykinesia, rigidity, resting tremor, and postural instability., ${ }^{4,5}$ Over time, changes in ambulation, functional mobility, and ability to perform activities of daily living can occur with a resultant decrease in individual's quality of life. ${ }^{6}$ Pharmacological and surgical intervention look to improve this disability process. ${ }^{7}$ In recent years, studies have also suggested the benefits of physical activity in patients with PD. ${ }^{8-14}$

Through research, we have begun to understand the mechanisms by which functional activity, training, and physical exercise facilitates improvement in motor behavior in patients with PD. Several mechanisms through animal and human studies have alluded to modulation of neuronal function and structure in promoting neuroplasticity and neurorestoration. ${ }^{11,15}$ These mechanisms include both adaptive and protective changes in the circuitry of the basal ganglia, involving both dopaminergic and glutaminergic pathways as well as brain-derived neurotrophic factors (BDNF), leading to long-term benefits and disease modification in PD. ${ }^{16,17}$

Through research, we have begun to establish guidelines for generalized exercise regimens including the addition of balance and strengthening, ${ }^{18,19}$ as well as use of flexibility training ${ }^{20}$ in patients with PD. However, in the recent decade, a number of clinical studies have also begun to investigate the effectiveness and feasibility of specific types of physical activity intervention. These intervention types include: amplitudespecific training (ie, LSVT BIG), ${ }^{21-24}$ rhythmic dance training (ie, tango), ${ }^{25,26}$ functional 
balance training (ie, yoga), ${ }^{27}$ and treadmill training (including body weight support training). ${ }^{28}$

This paper will aim to highlight strategies to encourage physical activity in PD patients, the effects of physical activity and exercise on the quality of life of individuals with PD, identify types of physical activity most recently and thoroughly supported by research and literature, and identify common barriers to participating in physical activity and ways to overcome barriers that may hinder participation in physical activity through the different stages of PD.

\section{Methods and materials}

A complete literature review was performed on PubMed that included the terms such as exercise and Parkinson's disease, Parkinson's and physical activity, Parkinson's, exercise and neuroplasticity, Parkinson's disease, exercise and quality of life, exercise and disease progression, dance and Parkinson's disease, Yoga and Parkinson's disease, Tai chi and Parkinson's disease, Parkinson's disease, animal models and exercise between 1970 and 2015; all peer-reviewed articles and abstracts were included.

\section{Animal studies and exercise}

In review of the literature, much of our understanding of the neurobiological changes in exercise was being derived from animal studies. These neurotoxin-based animal models have demonstrated potential effects of exercise in Parkinson's disease; those benefits included motor skill training, neuroplasticity, and neurorestoration. ${ }^{29-32}$ Increased dopamine levels and improved response to dopamine-replacement therapies as well as improvements noted in the dopamine handling and neurotransmission ${ }^{33-36}$ were documented in these animal models.

Studies have demonstrated neuroprotective effects of exercise in PD, though not completely understood this is implied through dopaminergic and/or downstream compensatory mechanisms, increased expression of BDNF, ${ }^{17,37-39}$ alterations in glutamatergic receptor expression are well known basis for neuronal death in many neurodegenerative diseases. ${ }^{40}$ Changes in glutamatergic neurotransmission induced via exercise, including changes in glutamate and glutamatergic receptor families such as NMDA or AMPA, are well-established, critical components of neuroplastic changes by altering glutamate release, glutamate receptor expression, which leads to attenuation of glutamatergic hyperexcitability. ${ }^{41-43}$ These alterations help restore normal synaptic plasticity of the neurodegenerative basal ganglia, resulting in restoration of motor behavior. ${ }^{44,45}$
Collectively, these studies demonstrate that alterations in dopaminergic and glutamatergic neurotransmission modulate corticostriatal hyperexcitability, which in turn leads to improvement of exercise-induced behavior.

\section{Human studies of exercise in PD}

In the recent decade, clinical studies of exercise in individuals with PD have generated a great deal of interest in the ability of exercise to perhaps restore brain function and/or modify disease $^{46,47}$ as well as the effect of exercise on response of dopamine-replacement therapies. ${ }^{48,49}$

Numerous studies support use of exercise in modulating brain function in individuals with $\mathrm{PD} .{ }^{50-53}$ Petzinger et $\mathrm{al}^{35,54,55}$ and several other researchers ${ }^{56,57}$ were able to demonstrate that intensive treadmill training over 24 sessions showed an improvement in gait velocity, stride length, step length, and hip and ankle joint excursion. Improvement of weight distribution during sit-to-stand through the use of transmagnetic stimulation during these treadmill training sessions showed exercise-induced lengthening of cortical changes. Also, effects of intensive treadmill training was similarly shown via positron emission tomography $18 \mathrm{~F}$-fallypride imaging, which was able to demonstrate increased dopamine $\mathrm{D}_{2}$ receptor expression via an increase in binding potential of $\mathrm{D}_{2}$ receptor expres$\operatorname{sion}^{58}$ in participants with PD. ${ }^{55}$

Other studies have shown that these changes might not necessarily be cortical but related to changes in behavior and generalized motor benefit perhaps owing to improvement in muscle memory. ${ }^{59,60}$

Accelerometer gait analysis ${ }^{61}$ is a valuable tool for obtaining quantitative information on motor deficits in PD with current applications of accelerometers in gait and balance evaluation, fall risk assessment, and mobility monitoring. Hence it provides an added objective and quantitative dimension to gait analysis when combined with clinical assessment ${ }^{62}$ for defining benefits of physical activity and rehab in patients with $\mathrm{PD}$.

The greatest impairment from PD is seen in the areas related to physical and social functioning. ${ }^{63}$ Effect of physical activity and exercise on health-related quality of life (HRQoL) of individuals with PD has been well established in the literature. ${ }^{12,64-66}$ Subsequently, there have been a number of recent studies exploring the effect of exercises for individuals with $\mathrm{PD}$, particularly in relation to motor behaviors and quality-of-life determinants. These studies have found links between exercise programs and improvement in several factors related to HRQoL ${ }^{67,68}$ as well as to individuals' 
perceived improvement in quality of life after engaging in an exercise program. ${ }^{13}$

In addition to the benefits of physical activity and exercise on motor symptoms of PD, benefits on nonmotor symptoms of PD including cognitive and affective benefits have been described. ${ }^{69-72}$ Although the link between exercise and improvement in quality of life for individuals with PD is becoming more accepted, the specific mechanism continues to be investigated.

\section{Types of physical activity and exercise most recently and best supported by research}

As research points to a positive effect of exercise on quality of life for individuals with PD, often patients want to know what type of exercises should be incorporated into their daily lives. Certain overall aspects of exercise have been demonstrated to consistently improve quality of life, including strengthening, balance, ${ }^{18,19}$ and flexibility training. ${ }^{20}$ Many recent studies have investigated different exercise types and their impact on PD symptomatology and HRQoL. These exercise types can be loosely categorized into several categories including amplitude-specific training (ie, LSVT $\mathrm{BIG}),{ }^{22-24}$ rhythmic dance training (ie, tango), functional balance training (ie, yoga), gait/treadmill training (including body weight support training), and other exercise programs such as boxing.

Amplitude-specific training emphasizes high-intensity, repetitive, progressively challenging activities in an attempt to counteract the commonly early seen symptoms of bradykinesia. ${ }^{24,60,73-75}$ Amplitude-specific training for individuals with PD has demonstrated an improvement in Unified Parkinson's Disease Rating Scale (UPDRS) scores, several aspects of ambulation including starting/stopping, and quality and degree of functional reach. ${ }^{18,66,76,77}$

Rhythmic dance training includes several styles of dance (tango, ballroom, etc). The rhythmic nature of the dancing is thought to have a positive effect on several aspects of movement in individuals with $\mathrm{PD}$ by emphasizing repetitive multidirectional stepping and balance, ${ }^{64}$ some have shown the power of cueing in freezing of gait and gait disturbances in PD. ${ }^{78,79}$ Both tango ${ }^{80,81}$ and ballroom dancing have been shown to have a positive effect on standing balance, UPDRS scores, and ambulation starting/stopping. ${ }^{82-84}$

Functional balance training includes exercise programs like yoga, tai chi, and boxing. Several studies demonstrate the positive effect of yoga ${ }^{85}$ and tai $\mathrm{chi}^{86,87}$ on gait and balance in PD patients. Some of these studies have also shown a trend toward reduction of depression score or increased awareness of emotional well-being. ${ }^{88}$

Studies involving the use of boxing as an intervention type demonstrated improvements in balance, gait, disability score, and quality-of-life scores for the majority of participants. Also, individuals with PD were able to demonstrate the ability to perform group therapy sessions and prolonged duration exercise sessions (more than 60 minutes) without difficulty, demonstrating endurance to perform these types of exercises. Therefore, perhaps a regular exercise regimen in itself improves endurance in PD. ${ }^{89}$

Sensorimotor agility exercise programs strive to incorporate several different types of functional balance training exercises (including tai chi, boxing, etc) to emphasize improved coordination, improved motor program selection, and improved sensory integration. ${ }^{21}$

Gait/treadmill training has also been investigated for its effect on quality of life, improvement in gait stride, and balance. Treadmill training through an external cue ${ }^{79}$ enhances rhythmicity and reduces variability in gait, and decreases stride/swing time variability, leading to a more stable gait. ${ }^{90}$ Intensive treadmill training has also demonstrated improvements in several aspects of motor deficit including UPDRS scores, gait speed, cadence, and perceived physical performance. ${ }^{28,50,91,92}$

In summary, all the different types of exercise programs have been shown to demonstrate improvement in movement impairments including balance, some areas of ambulation, as well as improvement for various aspects of quality of life. Each of the exercise programs incorporate varying amounts of focus on strengthening, balance, and flexibility. However, studies comparing the effect of one type of intervention over another are limited.

\section{Common barriers to participating in physical activity and exercise}

Literature has shown that both dose and intensity of exercise matter. ${ }^{68}$ The Centers for Disease Control and Prevention recommends that all older adults need at least 150 minutes a week of at least moderate intensity aerobic activity, such as brisk walking and muscle-strengthening activities on two or more days a week for important health benefits. ${ }^{93}$ Currently, a vast majority of patients do not have a regular exercise program.

Furthermore, patients with PD often report other barriers to participating in exercise programs, including fear of falling, lack of exercise knowledge, lack of motivation, low expectation, lack of time, lack of transportation, lack of monetary support, or difficulty with medical coverage. 


\section{Developing physical activity and exercise strategies for patients with PD \\ Education}

The role of physical activity and exercise in PD should be clearly communicated to our patients. Often, early into the diagnosis of PD, most physician communication centers on symptomology and medication management in the initial stages of PD. Care should be taken to also discuss physical activity as a modifying agent with a referral to an exercise specialist or physical therapist if the patient is unfamiliar with what or how to exercise. Support groups and structured educational seminars may also be helpful for newly diagnosed PD patients or family members. Community-based programs may be effective in alleviating some of the psychosocial limitations, as they not only offer a place for social support but also offer a way to have group exercise therapy.

\section{Prevention}

Traditionally, most referrals to rehabilitative services are initiated after PD patients report having significant changes in mobility (falls, fracture, or dependence on caregivers). However, the literature demonstrates the effect of different types of exercise programs and a dose-dependent effect on PD with more persistent and positive effects in patients with mild-to-moderate PD as compared to individuals with severe PD. ${ }^{24,57,66,94}$ This suggests that giving patients the tools to success starts with early implementation of exercise programs. Early referral to physical or occupational therapy may play a role in improving exercise knowledge, decreasing fear of falling with exercise, and setting up patients with home programs ${ }^{95}$ that may limit monetary or transportation barriers. The literature in itself has not documented the translation of physical therapy to home exercise, but guidance in exercise therapy and self-exercise will attempt to solve these problems.

\section{Customization}

Although the key diagnostic factors for individuals with PD are the same, each individual with PD may report varying degrees of functional loss or psychological impairment. The key to a successful development of an exercise regimen is to customize these programs taking into account an individual's barriers to exercise as well as their stage of severity. Patients with low disease severity may show improvements more quickly and may progress to nonsupervised therapies more efficiently. Patients with lower disease severity states can perform more challenging balance and gait exercises. However, patients with more progressed disease or higher disease severity states may require more supervision for longer duration in order to minimize environmental risks such as risk of falls. This is where regular health utilization of physical therapists in the form of either outpatient or home health rehabilitation remains a mode for more supervised exercise programs.

\section{Conclusion}

Early introduction to exercise therapy should be key and adjunctive to PD management. Through animal and human studies, disease-modifying benefits of exercise have been established. Behavioral strategies targeting barriers may help to improve compliance to exercise. Hence early implementation, early intervention, and early referral are important strategies to establishing and encouraging physical activity and exercise programs in PD.

\section{Disclosure}

The authors report no conflicts of interest in this work.

\section{References}

1. Garcia BG, Neely MD, Deutch AY. Cortical regulation of striatal medium spiny neuron dendritic remodeling in parkinsonism: modulation of glutamate release reverses dopamine depletion-induced dendritic spine loss. Cereb Cortex. 2010;20(10):2423-2432.

2. Lefaucheur JP. Motor cortex dysfunction revealed by cortical excitability studies in Parkinson's disease: influence of antiparkinsonian treatment and cortical stimulation. Clin Neurophysiol. 2005;116(2):244-253.

3. Bezard E, Boraud T, Bioulac B, Gross C. Compensatory effects of glutamatergic inputs to the substantia nigra pars compacta in experimental parkinsonism. Neuroscience. 1997;81(2):399-404.

4. Obeso JA, Marin C, Rodriguez-Oroz C, et al. The basal ganglia in Parkinson's disease: current concepts and unexplained observations. Ann Neurol. 2008;64(Suppl 2):S30-S46.

5. Hughes AJ, Daniel SE, Kilford L, Lees AJ. Accuracy of clinical diagnosis of idiopathic Parkinson's disease: a clinico-pathological study of 100 cases. J Neurol Neurosurg Psychiatry. 1992;55(3):181-184.

6. Rahman S, Griffin HJ, Quinn NP, Jahanshahi M. Quality of life in Parkinson's disease: the relative importance of the symptoms. Mov Disord. 2008;23(10):1428-1434.

7. Goetz CG, Poewe W, Rascol O, Sampaio C. Evidence-based medical review update: pharmacological and surgical treatments of Parkinson's disease: 2001 to 2004. Mov Disord. 2005;20(5):523-539.

8. Chen H, Zhang SM, Schwarzschild MA, Hernan MA, Ascherio A. Physical activity and the risk of Parkinson disease. Neurology. 2005;64(4):664-669.

9. Dibble LE, Foreman KB, Addison O, Marcus RL, LaStayo PC. Exercise and medication effects on persons with Parkinson disease across the domains of disability: a randomized clinical trial. J Neurol Phys Ther. 2015;39(2):85-92.

10. Dashtipour K, Johnson E, Kani C, et al. Effect of exercise on motor and nonmotor symptoms of Parkinson's disease. Parkinsons Dis. 2015;2015:586378.

11. Petzinger GM, Fisher BE, McEwen S, Beeler JA, Walsh JP, Jakowec MW. Exercise-enhanced neuroplasticity targeting motor and cognitive circuitry in Parkinson's disease. Lancet Neurol. 2013;12(7):716-726. 
12. Baatile J, Langbein W, Weaver F, Maloney C, Jost M. Effect of exercise on perceived quality of life of individuals with Parkinson's disease. J Rehabil Res Dev. 2000;37(5):529-534.

13. Rodrigues de Paula F, Teixeira-Salmela LF, Coelho de Morais Faria CD, Rocha de Brito P, Cardoso F. Impact of an exercise program on physical, emotional, and social aspects of quality of life of individuals with Parkinson's disease. Mov Disord. 2006;21(8):1073-1077.

14. Ashburn A, Fazakarley L, Ballinger C, Pickering R, McLellan LD, Fitton C. A randomised controlled trial of a home based exercise programme to reduce the risk of falling among people with Parkinson's disease. J Neurol Neurosurg Psychiatry. 2007;78(7):678-684.

15. Speelman AD, van de Warrenburg BP, van Nimwegen M, Petzinger GM, Munneke M, Bloem BR. How might physical activity benefit patients with Parkinson disease? Nat Rev Neurol. 2011;7(9):528-534.

16. Wu SY, Wang TF, Yu L, et al. Running exercise protects the substantia nigra dopaminergic neurons against inflammation-induced degeneration via the activation of BDNF signaling pathway. Brain Behav Immun. 2011;25(1):135-146.

17. Neeper SA, Gomez-Pinilla F, Choi J, Cotman CW. Physical activity increases mRNA for brain-derived neurotrophic factor and nerve growth factor in rat brain. Brain Res. 1996;726(1-2):49-56.

18. Hirsch MA, Toole T, Maitland CG, Rider RA. The effects of balance training and high-intensity resistance training on persons with idiopathic Parkinson's disease. Arch Phys Med Rehabil. 2003;84(8):1109-1117.

19. Glendinning D. A rationale for strength training in patients with Parkinson's disease. J Neurol Phys Ther. 1997;21(4):132-135.

20. Schenkman ML, Clark K, Xie T, Kuchibhatla M, Shinberg M, Ray L. Spinal movement and performance of a standing reach task in participants with and without Parkinson disease. Phys Ther. 2001;81(8):1400-1411.

21. King LA, Horak FB. Delaying mobility disability in people with Parkinson disease using a sensorimotor agility exercise program. Phys Ther. 2009;89(4):384-393.

22. Sapir S, Spielman JL, Ramig LO, Story BH, Fox C. Effects of intensive voice treatment (the Lee Silverman Voice Treatment [LSVT]) on vowel articulation in dysarthric individuals with idiopathic Parkinson disease: acoustic and perceptual findings. J Speech Lang Hear Res. 2007;50(4):899-912

23. Fox C, Ebersbach G, Ramig L, Sapir S. LSVT LOUD and LSVT BIG behavioral treatment programs for speech and body movement in Parkinson disease. Parkinsons Dis. 2012;2012:391946.

24. Farley BG, Koshland GF. Training BIG to move faster: the application of the speed-amplitude relation as a rehabilitation strategy for people with Parkinson's disease. Exp Brain Res. 2005;167(3):462-467.

25. Hackney ME, Kantorovich S, Levin R, Earhart GM. Effects of tango on functional mobility in Parkinson's disease: a preliminary study. J Neurol Phys Ther. 2007;31(4):173-179.

26. Hackney ME, Earhart GM. Health-related quality of life and alternative forms of exercise in Parkinson disease. Parkinsonism Relat Disord. 2009;15(9):644-648.

27. Taylor M. Yoga therapeutics in neurologic physical therapy: application to a patient with Parkinson's disease. J Neurol Phys Ther. 2001;25(2):55-62.

28. Protas EJ, Mitchell K, Williams A, Qureshy H, Caroline K, Lai EC. Gait and step training to reduce falls in Parkinson's disease. NeuroRehabilitation. 2005;20(3):183-190.

29. Cotman CW, Berchtold NC, Christie LA. Exercise builds brain health: key roles of growth factor cascades and inflammation. Trends Neurosci. 2007;30(9):464-472.

30. Hillman $\mathrm{CH}$, Erickson KI, Kramer AF. Be smart, exercise your heart: exercise effects on brain and cognition. Nat Rev Neurosci. 2008;9(1):58-65.

31. Ahlskog JE. Does vigorous exercise have a neuroprotective effect in Parkinson disease? Neurology. 2011;77(3):288-294.

32. Kramer AF, Erickson KI. Capitalizing on cortical plasticity: influence of physical activity on cognition and brain function. Trends Cogn Sci. 2007;11(8):342-348
33. Tillerson JL, Caudle WM, Reveron ME, Miller GW. Exercise induces behavioral recovery and attenuates neurochemical deficits in rodent models of Parkinson's disease. Neuroscience. 2003;119(3):899-911.

34. Adlard PA, Perreau VM, Engesser-Cesar C, Cotman CW. The timecourse of induction of brain-derived neurotrophic factor mRNA and protein in the rat hippocampus following voluntary exercise. Neurosci Lett. 2004;363(1):43-48

35. Petzinger GM, Walsh JP, Akopian G, et al. Effects of treadmill exercise on dopaminergic transmission in the 1-methyl-4-phenyl-1,2,3,6tetrahydropyridine-lesioned mouse model of basal ganglia injury. J Neurosci. 2007;27(20):5291-5300.

36. Vucckovic MG, Li Q, Fisher B, et al. Exercise elevates dopamine $\mathrm{D}_{2}$ receptor in a mouse model of Parkinson's disease: in vivo imaging with $\left[{ }^{18} \mathrm{~F}\right]$ fallypride. Mov Disord. 2010;25(16):2777-2784.

37. Vaynman S, Ying Z, Gomez-Pinilla F. Interplay between brain-derived neurotrophic factor and signal transduction modulators in the regulation of the effects of exercise on synaptic-plasticity. Neuroscience. 2003;122(3):647-657.

38. Berchtold NC, Chinn G, Chou M, Kesslak JP, Cotman CW. Exercise primes a molecular memory for brain-derived neurotrophic factor protein induction in the rat hippocampus. Neuroscience. 2005;133(3):853-861.

39. Adlard PA, Cotman CW. Voluntary exercise protects against stressinduced decreases in brain-derived neurotrophic factor protein expression. Neuroscience. 2004;124(4):985-992.

40. van Spronsen M, Hoogenraad CC. Synapse pathology in psychiatric and neurologic disease. Curr Neurol Neurosci Rep. 2010;10(3):207-214.

41. Dietrich MO, Mantese CE, Porciuncula LO, et al. Exercise affects glutamate receptors in postsynaptic densities from cortical mice brain. Brain Res. 2005;1065(1-2):20-25.

42. Pisani A, Centonze D, Bernardi G, Calabresi P. Striatal synaptic plasticity: implications for motor learning and Parkinson's disease. Mov Disord. 2005;20(4):395-402.

43. VanLeeuwen JE, Petzinger GM, Walsh JP, Akopian GK, Vuckovic M, Jakowec MW. Altered AMPA receptor expression with treadmill exercise in the 1-methyl-4-phenyl-1,2,3,6-tetrahydropyridine-lesioned mouse model of basal ganglia injury. J Neurosci Res. 2010;88(3):650-668.

44. Isaac JT, Ashby MC, McBain CJ. The role of the GluR2 subunit in AMPA receptor function and synaptic plasticity. Neuron. 2007;54(6):859-871.

45. Kessels HW, Malinow R. Synaptic AMPA receptor plasticity and behavior. Neuron. 2009;61(3):340-350.

46. Goodwin VA, Richards SH, Taylor RS, Taylor AH, Campbell JL. The effectiveness of exercise interventions for people with Parkinson's disease: a systematic review and meta-analysis. Mov Disord. 2008;23(5):631-640.

47. Ang ET, Wong PT, Moochhala S, Ng YK. Neuroprotection associated with running: is it a result of increased endogenous neurotrophic factors? Neuroscience. 2003;118(2):335-345.

48. Carter JH, Nutt JG, Woodward WR. The effect of exercise on levodopa absorption. Neurology. 1992;42(10):2042-2045.

49. Prodoehl J, Rafferty MR, David FJ, et al. Two-year exercise program improves physical function in Parkinson's disease: the PRET-PD randomized clinical trial. Neurorehabil Neural Repair. 2015;29(2):112-122.

50. Mehrholz J, Friis R, Kugler J, Twork S, Storch A, Pohl M. Treadmill training for patients with Parkinson's disease. Cochrane Database Syst Rev. 2010;1:CD007830.

51. Petzinger G, Holschneider D, Fisher B, et al. The effects of exercise on dopamine neurotransmission in Parkinson's disease: targeting neuroplasticity to modulate basal ganglia circuitry. Brain Plast. 2015;1(1):29-39.

52. Monteiro-Junior RS, Cevada T, Oliveira BR, et al. We need to move more: neurobiological hypotheses of physical exercise as a treatment for Parkinson's disease. Med Hypotheses. 2015;85(5):537-541.

53. David FJ, Robichaud JA, Leurgans SE, et al. Exercise improves cognition in Parkinson's disease: the PRET-PD randomized, clinical trial. Mov Disord. 2015;30(12):1657-1663. 
54. Petzinger GM, Fisher BE, Van Leeuwen JE, et al. Enhancing neuroplasticity in the basal ganglia: the role of exercise in Parkinson's disease. Mov Disord. 2010;25(Suppl 1):S141-S145.

55. Toy WA, Petzinger GM, Leyshon BJ, et al. Treadmill exercise reverses dendritic spine loss in direct and indirect striatal medium spiny neurons in the 1-methyl-4-phenyl-1,2,3,6-tetrahydropyridine (MPTP) mouse model of Parkinson's disease. Neurobiol Dis. 2014;63:201-209.

56. Fisher BE, Wu AD, Salem GJ, et al. The effect of exercise training in improving motor performance and corticomotor excitability in people with early Parkinson's disease. Arch Phys Med Rehabil. 2008;89(7):1221-1229.

57. Toole T, Maitland CG, Warren E, Hubmann MF, Panton L. The effects of loading and unloading treadmill walking on balance, gait, fall risk, and daily function in Parkinsonism. NeuroRehabilitation. 2005;20(4):307-322.

58. Fisher BE, Li Q, Nacca A, et al. Treadmill exercise elevates striatal dopamine $\mathrm{D}_{2}$ receptor binding potential in patients with early Parkinson's disease. Neuroreport. 2013;24(10):509-514.

59. Ridgel AL, Vitek JL, Alberts JL. Forced, not voluntary, exercise improves motor function in Parkinson's disease patients. Neurorehabil Neural Repair. 2009;23(6):600-608.

60. Ridgel AL, Peacock CA, Fickes EJ, Kim C-H. Active-assisted cycling improves tremor and bradykinesia in Parkinson's disease. Arch Phys Med Rehabil. 2012;93(11):2049-2054.

61. Yoneyama M, Kurihara Y, Watanabe K, Mitoma H. Accelerometry-based gait analysis and its application to parkinson's disease assessment. Part 2: a new measure for quantifying walking behavior. IEEE Trans Neural Syst Rehabil Eng. 2013;21(6):999-1005.

62. Culhane K, O'Connor M, Lyons D, Lyons G. Accelerometers in rehabilitation medicine for older adults. Age Ageing. 2005;34(6): 556-560.

63. Schrag A, Jahanshahi M, Quinn N. How does Parkinson's disease affect quality of life? A comparison with quality of life in the general population. Mov Disord. 2000;15(6):1112-1118.

64. De Dreu M, Van Der Wilk A, Poppe E, Kwakkel G, Van Wegen E. Rehabilitation, exercise therapy and music in patients with Parkinson's disease: a meta-analysis of the effects of music-based movement therapy on walking ability, balance and quality of life. Parkinsonism Relat Disord. 2012;18:S114-S119.

65. Uc E, Magnotta V, Johnson H, et al. Effects of aerobic exercise on striatum and substantia nigra in Parkinson's disease (S40. 007). Neurology. 2015;84(Supp1 14).

66. Ebersbach G, Ebersbach A, Edler D, et al. Comparing exercise in Parkinson's disease - the Berlin LSVT®BIG study. Mov Disord. 2010;25(12):1902-1908.

67. Dibble LE, Hale TF, Marcus RL, Gerber JP, LaStayo PC. High intensity eccentric resistance training decreases bradykinesia and improves quality of life in persons with Parkinson's disease: a preliminary study. Parkinsonism Relat Disord. 2009;15(10):752-757.

68. Oguh O, Eisenstein A, Kwasny M, Simuni T. Back to the basics: regular exercise matters in Parkinson's disease: results from the National Parkinson Foundation QII registry study. Parkinsonism Relat Disord. 2014;20(11):1221-1225.

69. Cruise KE, Bucks RS, Loftus AM, Newton RU, Pegoraro R, Thomas MG. Exercise and Parkinson's: benefits for cognition and quality of life. Acta Neurol Scand. 2011;123(1):13-19.

70. Barbour KA, Blumenthal JA. Exercise training and depression in older adults. Neurobiol Aging. 2005;26(Suppl 1):119-123.

71. De Moor MH, Beem AL, Stubbe JH, Boomsma DI, De Geus EJ. Regular exercise, anxiety, depression and personality: a population-based study. Prev Med. 2006;42(4):273-279.

72. Tanaka K, de Quadros AC, Santos RF, Stella F, Gobbi LTB, Gobbi S. Benefits of physical exercise on executive functions in older people with Parkinson's disease. Brain Cogn. 2009;69(2):435-441.
73. Fox CM, Ramig LO, Ciucci MR, Sapir S, McFarland DH, Farley BG. The science and practice of LSVT/LOUD: neural plasticity-principled approach to treating individuals with Parkinson disease and other neurological disorders. Semin Speech Lang. 2006;27(4):283-299.

74. Ridgel AL, Phillips RS, Walter BL, Discenzo FM, Loparo KA. Dynamic high-cadence cycling improves motor symptoms in Parkinson's disease. Front Neurol. 2015;6:194.

75. Tuccitto JA, Guse LC. On "Application of LSVT BIG intervention..." Janssens J, Malfroid KN, Myffeler T, et al. Phys Ther. 2014;94:1014-1023 [comment]. Phys Ther. 2014;94(12):1828-1829.

76. Farley BG, Fox CM, Ramig LO, McFarland DH. Intensive amplitudespecific therapeutic approaches for Parkinson's disease: toward a neuroplasticity-principled rehabilitation model. Top Geriatr Rehabil. 2008;24(2):99-114.

77. Falvo MJ, Schilling BK, Earhart GM. Parkinson's disease and resistive exercise: rationale, review, and recommendations. Mov Disord. 2008;23(1):1-11

78. Rubinstein TC, Giladi N, Hausdorff JM. The power of cueing to circumvent dopamine deficits: a review of physical therapy treatment of gait disturbances in Parkinson's disease. Mov Disord. 2002;17(6):1148-1160.

79. Duncan RP, Earhart GM. Randomized controlled trial of communitybased dancing to modify disease progression in Parkinson disease. Neurorehabil Neural Repair. 2012;26(2):132-143.

80. Romenets SR, Anang J, Fereshtehnejad S-M, Pelletier A, Postuma R. Tango for treatment of motor and non-motor manifestations in parkinson's disease: a randomized control study. Complement Ther Med. 2015;23(2):175-184.

81. Hackney ME, Kantorovich S, Earhart GM. A study on the effects of Argentine tango as a form of partnered dance for those with Parkinson disease and the healthy elderly. Am J Dance Ther. 2007;29(2):109-127.

82. Hackney ME, Earhart GM. Effects of dance on movement control in Parkinson's disease: a comparison of Argentine tango and American ballroom. J Rehabil Med. 2009;41(6):475-481.

83. Shanahan J, Morris ME, Bhriain ON, Saunders J, Clifford AM. Dance for people with Parkinson disease: what is the evidence telling us? Arch Phys Med Rehabil. 2015;96(1):141-153.

84. Earhart GM. Dance as therapy for individuals with Parkinson disease. Eur J Phys Rehabil Med. 2009;45(2):231-238.

85. Colgrove Y, Sharma N, Kluding P, Potter D, Imming K, VandeHoef J. Effect of yoga on motor function in people with Parkinson's disease: a randomized, controlled pilot study. J Yoga Phys Ther. 2012;2(2):112.

86. Gao Q, Leung A, Yang Y, et al. Effects of Tai Chi on balance and fall prevention in Parkinson's disease: a randomized controlled trial. Clin Rehabil. 2014;28(8):748-753.

87. Li F, Harmer P, Fitzgerald K, et al. Tai chi and postural stability in patients with Parkinson's disease. N Engl J Med. 2012;366(6):511-519.

88. Sharma NK, Robbins K, Wagner K, Colgrove YM. A randomized controlled pilot study of the therapeutic effects of yoga in people with Parkinson's disease. Int J Yoga. 2015;8(1):74-79.

89. Combs SA, Diehl MD, Staples WH, et al. Boxing training for patients with Parkinson disease: a case series. Phys Ther. 2011;91(1):132-142.

90. Frenkel-Toledo S, Giladi N, Peretz C, Herman T, Gruendlinger L, Hausdorff JM. Treadmill walking as an external pacemaker to improve gait rhythm and stability in Parkinson's disease. Mov Disord. 2005;20(9):1109-1114.

91. van Wegen E, de Goede C, Lim I, et al. The effect of rhythmic somatosensory cueing on gait in patients with Parkinson's disease. Journal Neurol Sci. 2006;248(1-2):210-214.

92. Herman T, Giladi N, Gruendlinger L, Hausdorff JM. Six weeks of intensive treadmill training improves gait and quality of life in patients with Parkinson's disease: a pilot study. Arch Phys Med Rehabil. 2007;88(9):1154-1158. 
93. Haskell WL, Lee IM, Pate RR, et al. Physical activity and public health: updated recommendation for adults from the American College of Sports Medicine and the American Heart Association. Med Sci Sports Exerc. 2007;39(8):1423-1434.

94. Abbruzzese G, Marchese R, Avanzino L, Pelosin E. Rehabilitation for Parkinson's disease: Current outlook and future challenges. Parkinsonism Relat Disord. 2016;22:S60-S64.
95. Nakae H, Tsushima H. Effects of home exercise on physical function and activity in home care patients with Parkinson's disease. JPhys Ther Sci. 2014;26(11):1701-1706.

Journal of Parkinsonism \& Restless Legs Syndrome

\section{Publish your work in this journal}

Journal of Parkinsonism and Restless Legs Syndrome is an online, open access, peer-reviewed journal. The journal publishes review articles, historical reviews, original research articles, case reports, letters to the editor, clinical teaching cases, neuroradiology highlights, neuropathology highlights, neuropsychiatry highlights, autobiographies, conference

\section{Dovepress}

proceedings, abstracts and book reviews. The manuscript management system is completely online and includes a very quick and fair peerreview system, which is all easy to use. Visit http://www.dovepress.com/ testimonials.php to read real quotes from published authors.

Submit your manuscript here: http://www.dovepress.com/journal-of-parkinsonism--restless-legs-syndrome-journal 